\title{
Article \\ Diurnal Response of Photosystem I to Fluctuating Light Is Affected by Stomatal Conductance
}

\author{
Ting-Yu Li ${ }^{1,2,+}$, Qi Shi ${ }^{2,3,+}$, Hu Sun ${ }^{2,3}$, Ming Yue ${ }^{1}$, Shi-Bao Zhang ${ }^{2, *}$ and Wei Huang ${ }^{2, *}$ (D) \\ 1 School of Life Sciences, Northwest University, Xi'an 710069, China; litingyu@mail.kib.ac.cn (T.-Y.L.); \\ yueming@nwu.edu.cn (M.Y.) \\ 2 Kunming Institute of Botany, Chinese Academy of Sciences, Kunming 650201, China; \\ shiqi@mail.kib.ac.cn (Q.S.); sunhu19@mails.ucas.ac.cn (H.S.) \\ 3 University of Chinese Academy of Sciences, Beijing 100049, China \\ * Correspondence: sbzhang@mail.kib.ac.cn (S.-B.Z.); huangwei@mail.kib.ac.cn (W.H.); \\ Tel.: +86-0871-65223128 (W.H.) \\ + These authors contributed equally to this study.
}

check for updates

Citation: Li, T.-Y.; Shi, Q.; Sun, H.; Yue, M.; Zhang, S.-B.; Huang, W.

Diurnal Response of Photosystem I to Fluctuating Light Is Affected by Stomatal Conductance. Cells 2021, 10, 3128. https://doi.org/10.3390/ cells10113128

Academic Editor: Hazem M. Kalaji

Received: 14 September 2021

Accepted: 27 October 2021

Published: 11 November 2021

Publisher's Note: MDPI stays neutral with regard to jurisdictional claims in published maps and institutional affiliations.

Copyright: (c) 2021 by the authors. Licensee MDPI, Basel, Switzerland. This article is an open access article distributed under the terms and conditions of the Creative Commons Attribution (CC BY) license (https:/ / creativecommons.org/licenses/by/ $4.0 /)$.

\begin{abstract}
Upon a sudden transition from low to high light, electrons transported from photosystem II (PSII) to PSI should be rapidly consumed by downstream sinks to avoid the over-reduction of PSI. However, the over-reduction of PSI under fluctuating light might be accelerated if primary metabolism is restricted by low stomatal conductance. To test this hypothesis, we measured the effect of diurnal changes in stomatal conductance on photosynthetic regulation under fluctuating light in tomato (Solanum lycopersicum) and common mulberry (Morus alba). Under conditions of high stomatal conductance, we observed PSI over-reduction within the first $10 \mathrm{~s}$ after transition from low to high light. Lower stomatal conductance limited the activity of the Calvin-Benson-Bassham cycle and aggravated PSI over-reduction within $10 \mathrm{~s}$ after the light transition. We also observed PSI overreduction after transition from low to high light for $30 \mathrm{~s}$ at the low stomatal conductance typical of the late afternoon, indicating that low stomatal conductance extends the period of PSI over-reduction under fluctuating light. Therefore, diurnal changes in stomatal conductance significantly affect the PSI redox state under fluctuating light. Moreover, our analysis revealed an unexpected inhibition of cyclic electron flow by the severe over-reduction of PSI seen at low stomatal conductance. In conclusion, stomatal conductance can have a large effect on thylakoid reactions under fluctuating light.
\end{abstract}

Keywords: electron transport; fluctuating light; photosynthesis; photosystem I; stomatal conductance

\section{Introduction}

Fluctuating light (FL) is the typical light condition under natural field conditions [1]. A sudden drop in light intensity will cause a decrease in $\mathrm{CO}_{2}$ assimilation rate without photoinhibition $[2,3]$. By contrast, when the light intensity abruptly increases, the resulting rapid rise in photosystem II (PSII) electron flow is accompanied by relatively slower kinetics of $\mathrm{CO}_{2}$ assimilation [4]. As a result, ATP and NADPH produced by linear electron flow cannot be immediately consumed by the primary metabolism. Such imbalance between light and dark reactions then leads to the accumulation of electrons in PSI, which manifests as PSI over-reduction [5-7]. Under such conditions, the transfer of electrons from PSI electron carriers to oxygen $\left(\mathrm{O}_{2}\right)$ increases, producing reactive oxygen species (ROS) [8]. Because antioxidant systems cannot immediately scavenge the ROS generated within PSI [9], the FL-induced over-reduction of PSI causes significant PSI photoinhibition [6,10-12]. Owing to the important role of PSI in the operation of photosynthetic electron transport, PSI photoinhibition significantly suppresses $\mathrm{CO}_{2}$ assimilation, photoprotection, and plant growth [13-16].

To protect PSI under FL, plants have evolved alternative electron flow pathways to partially alleviate PSI over-reduction. In general, cyclic electron flow (CEF) around PSI 
is thought to be the main player regulating the PSI redox state under FL [8]. During CEF around PSI, electrons from ferredoxin are transported to the plastoquinone pool and are mediated by the PROTON GRADIENT REGULATION5 (PGR5)/PGR5-LIKE1 (PGRL1) and NAD(P)H DEHYDROGENASE (NDH) pathways [17,18], which are coupled to proton translocation from the stroma to the thylakoid lumen [19-21]. Therefore, CEF generates a proton gradient $(\Delta \mathrm{pH})$ across the thylakoid membrane without NADPH production. When transitioning from low to high light, $\mathrm{CEF}$ is rapidly activated to help with $\Delta \mathrm{pH}$ formation [22-24], which not only downregulates the oxidation of plastoquinone but also enhances the ATP/NADPH production ratio [25], both of which can prevent uncontrolled PSI over-reduction and thus protect PSI under FL [6]. However, CEF cannot avoid a transient PSI over-reduction under FL in many angiosperms $[5,6,26]$, suggesting that the PSI redox state under FL is also largely affected by the electrons downstream of PSI [27-29]. In angiosperms, electrons in PSI can be transported to $\mathrm{NADP}^{+}$and $\mathrm{O}_{2}$ [30]. The former is dependent on the operation of primary metabolism including $\mathrm{CO}_{2}$ fixation and photorespiration [31], whereas the latter is attributed to the water-water cycle [32]. The activity of the water-water cycle is negligible in most angiosperms [33-35], although it can significantly regulate PSI redox state under FL in some plants, such as those in the Camellia genus [36], Bryophyllum pinnatum [37], and the orchid Dendrobium officinale [38]. Therefore, the outflow of electrons in PSI under FL largely relies on the operation of primary metabolism. However, the effect of $\mathrm{CO}_{2}$ assimilation on the regulation of PSI redox state under FL is not well known.

Many studies have examined photosynthetic regulation under FL in the model plants Arabidopsis (Arabidopsis thaliana) and rice (Oryza sativa) grown under constant light $[4,6,8,29,39,40]$. However, the diurnal photosynthetic regulation under FL in wild plants grown under full sunlight has rarely been investigated. Under natural field conditions, diurnal changes in photosynthetic $\mathrm{CO}_{2}$ assimilation rate are largely affected by stomatal conductance [41-43]. Stomatal conductance determines the extent of $\mathrm{CO}_{2}$ diffusion from the air to the intercellular space. A decrease in stomatal conductance lowers the total $\mathrm{CO}_{2}$ diffusion conductance, thus restricting $\mathrm{CO}_{2}$ fixation owing to the low $\mathrm{CO}_{2}$ concentration in chloroplasts [44]. Under such conditions, the consumption of NADPH is blocked, leading to a decrease in the $\mathrm{NADP}^{+} / \mathrm{NADPH}$ ratio. Because the linear electron flow is largely controlled by the NADP ${ }^{+} / \mathrm{NADPH}$ ratio [45], electron flow from PSI to $\mathrm{NADP}^{+}$at low stomatal conductance is limited by the lack of NADP ${ }^{+}$[46]. Therefore, when stomatal conductance decreases, the restriction of $\mathrm{CO}_{2}$ fixation will suppress the outflow of electrons from PSI to $\mathrm{NADP}^{+}$, aggravating PSI over-reduction under FL. Thus, we speculate that stomatal conductance plays an important role in the regulation of the PSI redox state under FL and that the response of PSI to FL is likely affected by diurnal changes in stomatal conductance.

In this study, we measured diurnal photosynthetic regulation under FL in tomato (Solanum lycopersicum) and common mulberry (Morus alba). The main aims were to (1) determine whether a decrease in stomatal conductance accelerates PSI over-reduction under FL and (2) assess whether the diurnal response of PSI to FL is controlled by stomatal conductance.

\section{Materials and Methods}

\subsection{Plant Materials}

Tomato (Solanum lycopersicum Miller cv. Hupishizi) and common mulberry (Morus alba) plants were cultivated in full sunlight. The day/night air temperatures were approximately $30{ }^{\circ} \mathrm{C} / 20^{\circ} \mathrm{C}$, and the maximum sunlight intensity at noon was approximately $2000 \mu \mathrm{mol}$ photons $\mathrm{m}^{-2} \mathrm{~s}^{-1}$ (measured by a Li-1400 datalogger, Li-Cor Biosciences, Lincoln, NE, USA). Seedlings were grown in plastic pots with humus soil with an initial soil $\mathrm{N}$ content of $2.1 \mathrm{mg} / \mathrm{g}$. Plants were fertilized with Peter's Professional water-soluble fertilizer (N:P:K = 15:4.8:24.1) once every 2 days. To prevent any water stress, the plants were watered every day. We used $F_{\mathrm{v}} / F_{\mathrm{m}}$ to quantify stress. All leaves used for measurements 
had $F_{\mathrm{v}} / F_{\mathrm{m}}$ values higher than 0.80 . The youngest fully developed leaves were used for measurements.

\subsection{Experimental Design}

In a preliminary experiment, stomatal conductance at 15:00 and 18:00 was measured in tomato leaves, which revealed that stomata were closed at 18:00 relative to 15:00. Furthermore, the photosynthetic response to FL in tomato leaves was significantly different at 15:00 and 18:00, indicating that the PSI redox state under FL can be affected by stomatal conductance. To confirm this finding, diurnal photosynthetic responses to FL were measured in the wild plant Morus alba. After measurement of incident stomatal conductance, leaves were exposed to a high light intensity of 1809 (or 1455) $\mu \mathrm{mol}$ photons $\mathrm{m}^{-2} \mathrm{~s}^{-1}$ for $5 \mathrm{~min}$ to activate photosynthetic electron sinks. Afterwards, leaves were exposed to FL alternating between 59 and 1809 (or 1455) $\mu \mathrm{mol}$ photons $\mathrm{m}^{-2} \mathrm{~s}^{-1}$ every $2 \mathrm{~min}$. For leaves of Morus alba, the light saturation point is approximately $1455 \mu \mathrm{mol}$ photons $\mathrm{m}^{-2} \mathrm{~s}^{-1}$. For leaves of tomato, $1809 \mu \mathrm{mol}$ photons $\mathrm{m}^{-2} \mathrm{~s}^{-1}$ is needed for maximum photosynthesis.

\subsection{Stomatal Conductance Measurements}

The diurnal changes in stomatal conductance were measured with a leaf porometer (SC-1 porometer; Decagon Devices, Inc., Pullman, WA, USA) on intact leaves. The incident stomatal conductance was measured under ambient sunlight.

\subsection{PSI and PSII Measurements}

We used a Dual-PAM 100 measuring system (Heinz Walz, German) to measure PSI and PSII parameters under atmospheric $\mathrm{CO}_{2}$ conditions [47]. The $635 \mathrm{~nm}$ actinic illumination from an LED array was used as the light source. A 5 min dark incubation was used to measure $P_{\mathrm{m}}$. The PSI parameters were calculated as follows: $\mathrm{Y}(\mathrm{I})=\left(P_{\mathrm{m}}{ }^{\prime}-P\right) / P_{\mathrm{m}}$; $\mathrm{Y}(\mathrm{ND})=P / P_{\mathrm{m}} ; \mathrm{Y}(\mathrm{NA})=\left(P_{\mathrm{m}}-P_{\mathrm{m}}{ }^{\prime}\right) / P_{\mathrm{m}} . \mathrm{Y}(\mathrm{I})$, the quantum yield of PSI photochemistry; $Y(N D)$, the quantum yield of PSI non-photochemical energy dissipation due to donor side limitation; Y(NA), the quantum yield of PSI non-photochemical energy dissipation due to acceptor side limitation. The effective quantum yield of PSII photochemistry was calculated as $\mathrm{Y}(\mathrm{II})=\left(F_{\mathrm{m}}{ }^{\prime}-F_{\mathrm{s}}\right) / F_{\mathrm{m}}{ }^{\prime}$. The relative photosynthetic electron transport rate through PSI and PSII was calculated as: ETRI $=\mathrm{PPFD} \times \mathrm{Y}(\mathrm{I}) \times 0.84 \times 0.5$; ETRII $=$ PPFD $\times Y(I I) \times 0.84 \times 0.5$. ETRI minus ETRII was assumed to be the rate of CEF.

\subsection{Statistical Analysis}

All results are shown as mean values of five individual experiments. Tukey's multiple comparison test was used to determine the significant differences between different treatments $(\alpha=0.05)$. The software SigmaPlot 10.0 was used for graphing and fitting.

\section{Results}

\subsection{A Decrease in Stomatal Conductance Induces PSI Over-Reduction under FL in Tomato}

We measured the photosynthetic responses to FL at 15:00 and 18:00 in tomato leaves. The stomatal conductance at 18:00 was much lower than that at 15:00 (Figure 1A), which was accompanied by a decrease in maximum PSII electron flow (ETRII $\max$ ) under FL (Figure 1B). Within $10 \mathrm{~s}$ after the transition from 59 to $1809 \mu \mathrm{mol}$ photons $\mathrm{m}^{-2} \mathrm{~s}^{-1}$, the quantum yield of PSI non-photochemical energy dissipation due to the donor side limitation (Y(ND)) increased from 0 to approximately 0.5 at 15:00, but only reached approximately 0.1 at 18:00 (Figure 1C). This moderate rise in Y(ND) at 18:00 led to severe PSI over-reduction, as indicated by the high value measured for the quantum yield of PSI non-photochemical energy dissipation due to the acceptor side limitation (Y(NA)) (Figure 1D). Y(NA) then decreased to its lowest value starting $30 \mathrm{~s}$ after the light transition at 15:00, but remained high at 18:00. These results indicated that the PSI redox state under FL changed during diurnal photosynthesis. When stomata were closed at 18:00, ETRII was not affected under low light but decreased by half under high light compared with values obtained 
at 15:00 (Figure 1E). To analyze the effect of stomatal closure on CEF performance under FL, we evaluated CEF by subtracting ETRII from ETRI in accordance with established published methods [48,49], although Y(I) can be under/over-estimated depending on the redox state of PC [50,51]. Under low light, CEF activation did not differ between 15:00 and 18:00. However, after transition from low to high light for $10 \mathrm{~s}$, CEF rapidly increased to reach its maximum value at 15:00, but showed a much more modest rise at 18:00 (Figure 1F). CEF required a full $30 \mathrm{~s}$ after the transition to increase to its peak value at 18:00. Therefore, lower stomatal conductance substantially influenced the activation speed of CEF under FL.
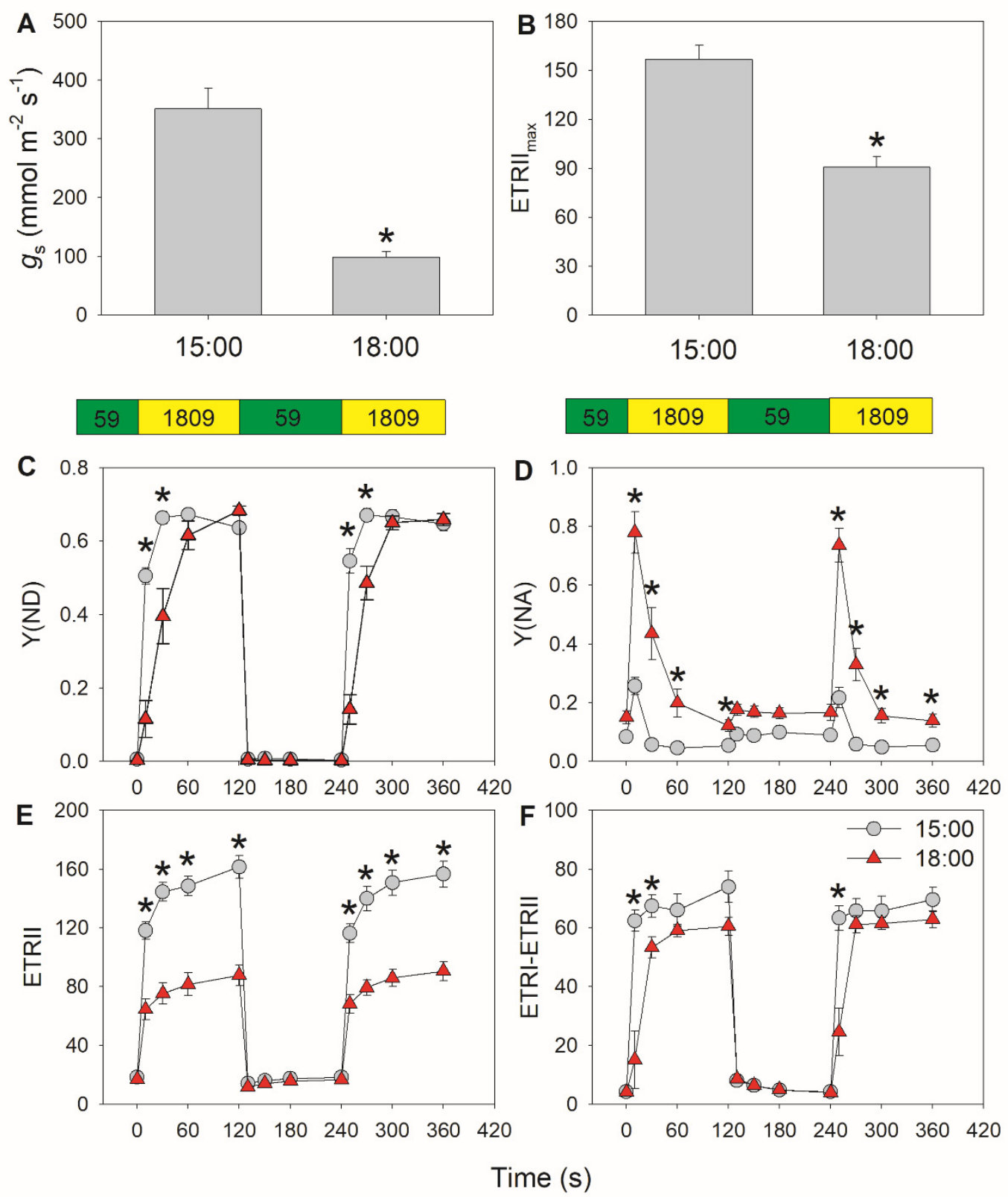

Figure 1. Assessment of diurnal photosynthetic performance in tomato leaves measured at 15:00 and 18:00: (A) stomatal conductance $\left(g_{\mathrm{s}}\right)$; (B) maximum electron transport rate through PSII (ETRII $\max$ ); (C-F) changes in photosynthetic parameters during fluctuating light alternating between 59 and $1809 \mu \mathrm{mol}$ photons $\mathrm{m}^{-2} \mathrm{~s}^{-1}$; (C) Y(ND), quantum yield of PSI non-photochemical energy dissipation due to the donor side limitation; (D) Y(NA), quantum yield of PSI non-photochemical energy dissipation due to the acceptor side limitation; (E) ETRI, electron transport rate through PSI; (F) estimated CEF performance, calculated as ETRI-ETRII. Asterisk indicates a significant difference between 15:00 and 18:00 samples. Data are shown as mean \pm standard error (SE, $n=5)$. 
Because the decreases in stomatal conductance and ETRII were accompanied by variation in $Y(\mathrm{NA})$ under FL, we examined the relationships between stomatal conductance, ETRII, and Y(NA) after transition from low to high light for 10 and $30 \mathrm{~s}$. As shown in Figure 2, low levels of stomatal conductance and ETRII max $_{\text {were }}$ associated with an increase in Y(NA) within the first $30 \mathrm{~s}$ after transition from low to high light. With the increases

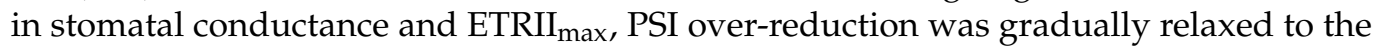
minimal value of approximately 0.1. These results suggest that restricting $\mathrm{CO}_{2}$ fixation significantly aggravates PSI over-reduction under FL. Furthermore, the severe PSI overreduction observed after transition from low to high light for $10 \mathrm{~s}$ at 18:00 inhibited the activation of CEF (Figure 3). Once PSI over-reduction was relaxed, CEF was fully activated. Therefore, the activation of CEF in high-light phases under FL is likely affected by PSI redox state.
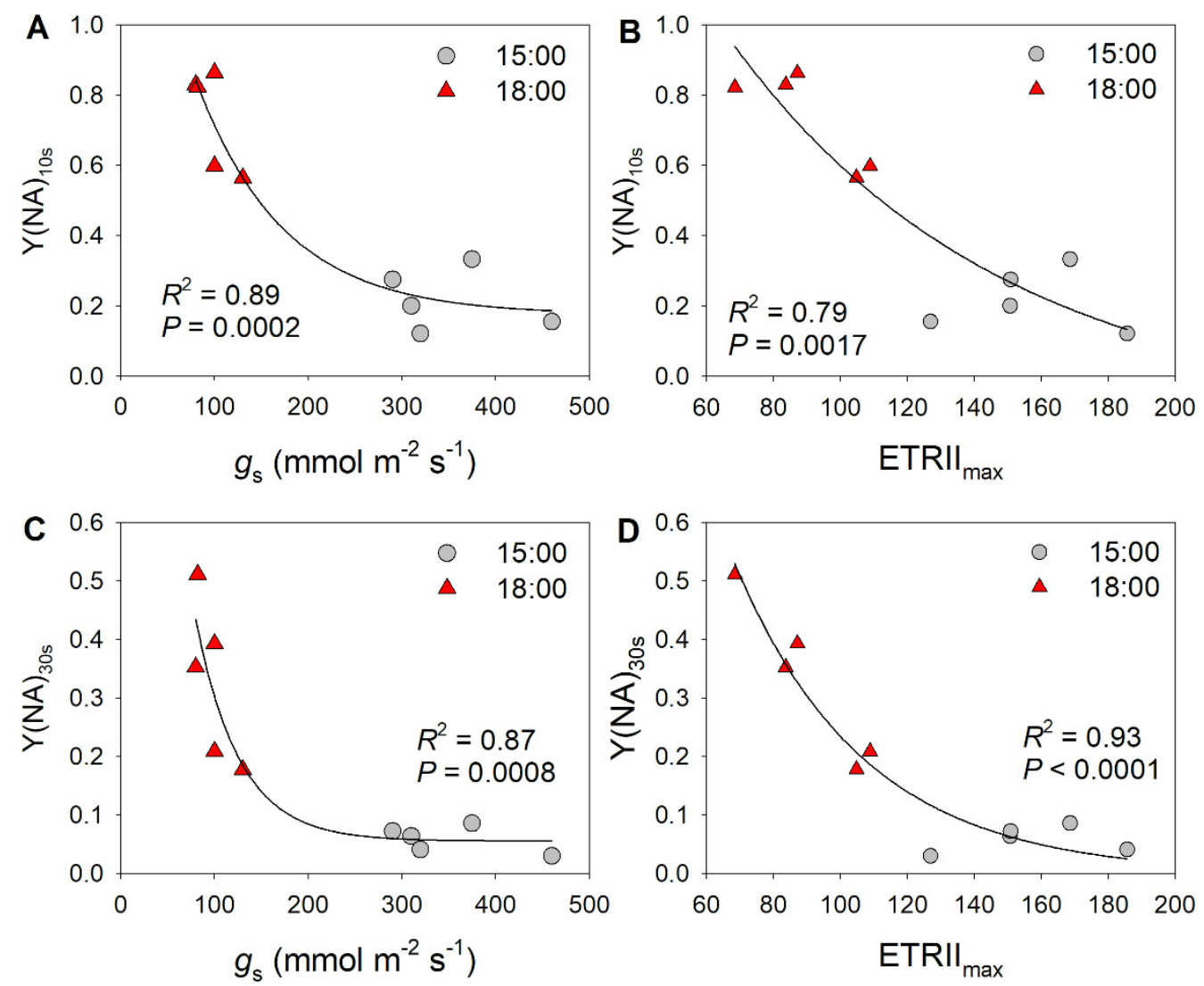

Figure 2. Exploration of correlations between PSI redox state and photosynthetic parameters: relationship between (A) stomatal conductance $\left(g_{\mathrm{s}}\right)$ and $\mathrm{Y}(\mathrm{NA})$ after transition from low to high light for $10 \mathrm{~s}\left(\mathrm{Y}(\mathrm{NA})_{10 \mathrm{~s}}\right.$ ), between (B) maximum electron transport rate through PSII (ETRII $\max$ ) and $\mathrm{Y}(\mathrm{NA})_{10 \mathrm{~s}}$, between $(\mathrm{C})$ stomatal conductance $\left(g_{\mathrm{s}}\right)$ and $\mathrm{Y}(\mathrm{NA})$ after transition from low to high light for $30 \mathrm{~s}\left(\mathrm{Y}(\mathrm{NA})_{30 \mathrm{~s}}\right)$, and between (D) ETRII $\max$ and $\mathrm{Y}(\mathrm{NA})_{30 \mathrm{~s}}$ in tomato leaves. The data for Y(NA) were taken from the second low/high light cycle, as shown in Figure 1. 

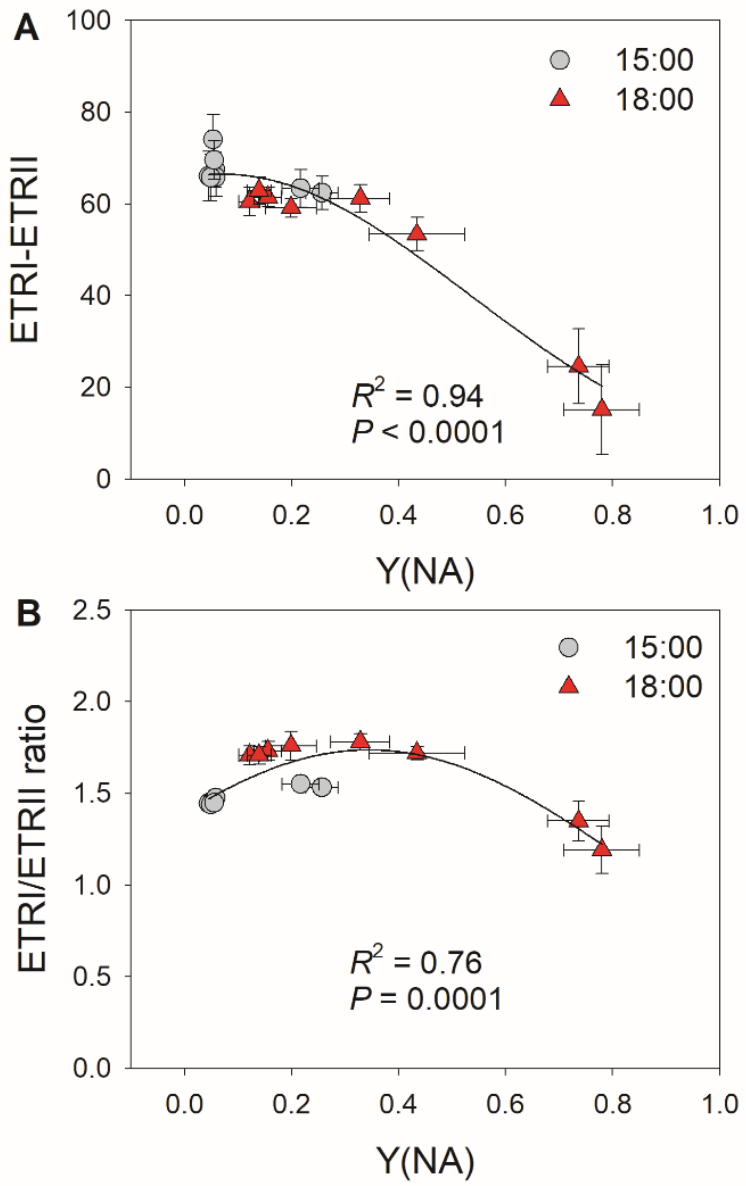

Figure 3. Relationships between (A) Y(NA) and ETRI-ETRII and between (B) Y(NA) and the ETRI/ERTII ratio during the high light phases under fluctuating light in tomato leaves. Data are shown as mean \pm SE $(n=5)$.

\subsection{Diurnal Response of PSI to FL in Morus alba Is Controlled by Stomatal Conductance}

To confirm the findings obtained in tomato, we examined the diurnal photosynthetic regulation under FL in the wild plant Morus alba. Stomatal conductance significantly decreased at 20:00 when compared with other sampling times (Figure 4A) and was associated with the smallest value for ETRII $\max$ (Figure 4B). When transitioning from low to high light, $\mathrm{Y}(\mathrm{ND})$ did not increase to its maximum value within the first $10 \mathrm{~s}$, but instead required a full $30 \mathrm{~s}$ to do so (Figure $4 \mathrm{C}$ ), leading to the concomitant increase in $\mathrm{Y}(\mathrm{NA})_{10 \mathrm{~s}}$ after the transition (Figure 4D). These results indicate that PSI is over-reduced under FL in M. alba. Furthermore, $Y(N D)$ increased much slower at 20:00 than at other time points, resulting in sustained high Y(NA) levels under FL. Therefore, stomatal closure in the late afternoon aggravated PSI over-reduction under FL. The ETRII values after transition to high light decreased in the late afternoon (Figure $4 \mathrm{E}$ ), suggesting that the $\mathrm{CO}_{2}$ assimilation rate is largely restricted by stomatal conductance. After transition to high light, $\mathrm{CEF}$ first increased to its peak value after $10 \mathrm{~s}$, which was followed by a gradual decrease to reach its minimal value after $120 \mathrm{~s}$ at all time points, except for 20:00 (Figure 4F). The activation of CEF at 20:00 during high light phases was higher than at other time points. 

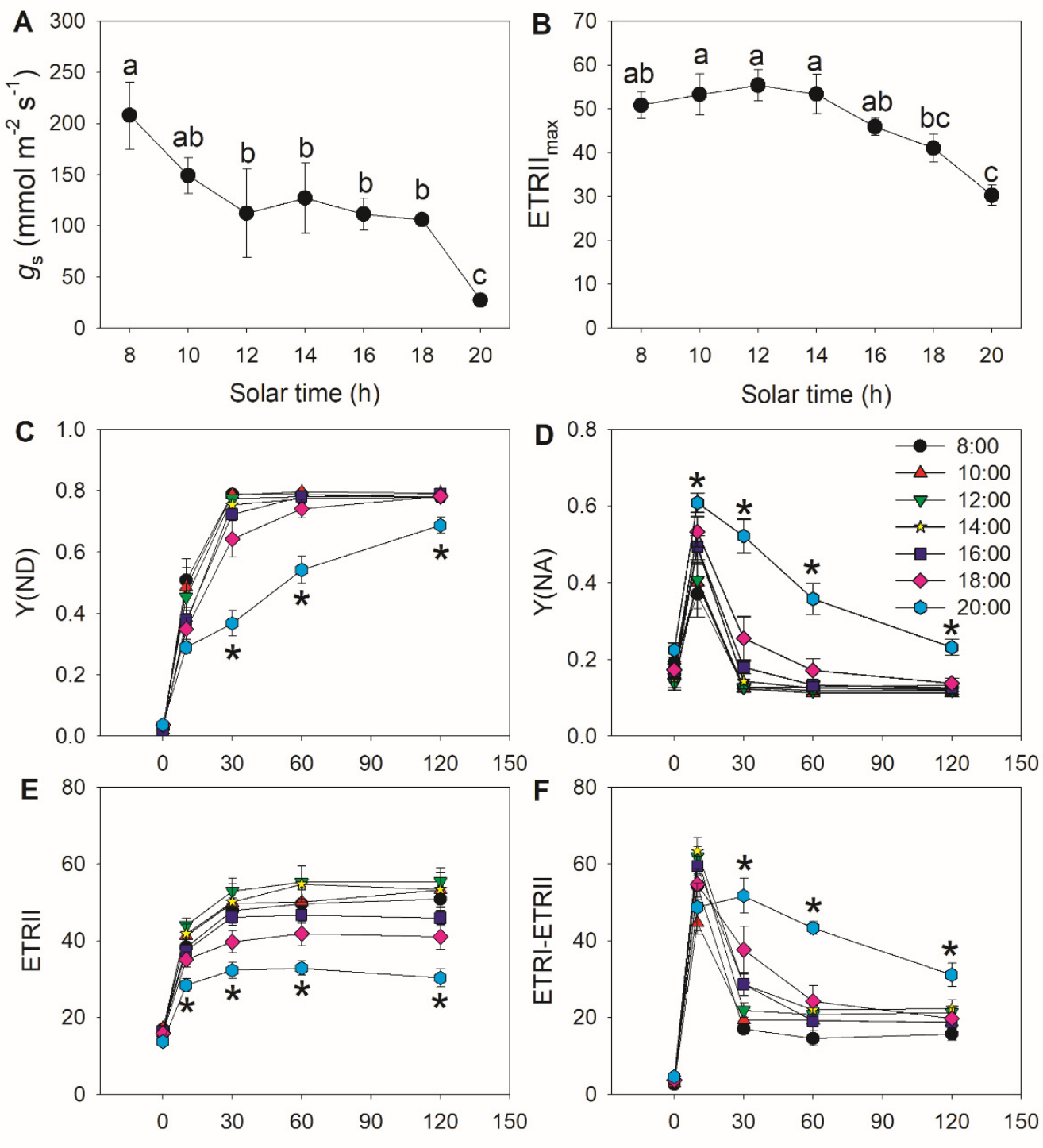

Time after transition from LL to $\mathrm{HL}$ (s)

Figure 4. Diurnal variation in photosynthetic performance of $M$. alba leaves: (A) stomatal conductance $\left(g_{\mathrm{s}}\right)$. (B) Maximum electron transport rate through PSII (ETRII $\max$ ). (C-F) Changes in photosynthetic parameters during fluctuating light alternating between 59 and $1455 \mu \mathrm{mol}$ photons $\mathrm{m}^{-2} \mathrm{~s}^{-1}$. (C) Y(ND), quantum yield of PSI non-photochemical energy dissipation due to donor side limitation. (D) Y(NA), quantum yield of PSI non-photochemical energy dissipation due to acceptor side limitation. (E) ETRI, electron transport rate through PSI. (F) Estimated CEF performance, calculated as ETRI-ETRII. In (A) and (B), different letters indicate significant differences. In C-F, asterisk indicates a significant difference between 20:00 and the other times. Data are shown as mean $\pm \operatorname{SE}(n=6)$.

We determined that the extent of PSI over-reduction after transition to high light was negatively correlated with stomatal conductance (Figure 5A,B), suggesting that the diurnal response of PSI to FL is largely driven by stomatal conductance. Furthermore, we detected negative relationships between ETRII max and Y(NA) during the high light phase (Figure 5C,D), indicating that the light use efficiency significantly influences the PSI redox state under FL. These results suggest that stomatal conductance has a large effect on the PSI redox state under FL by modulating light use efficiency. During high light phases, CEF activation was strongly and positively correlated with the PSI redox state (Figure 6A), as a higher $\mathrm{Y}$ (NA) was accompanied by higher CEF activation. When PSI was over-reduced after the transition to high light, the contribution of CEF to total photosynthetic electron transport rose (Figure 6B), which favored the formation of $\Delta \mathrm{pH}$ and alleviated PSI over- 
reduction. Once PSI over-reduction was fully relieved, the CEF activation state decreased, which prevented over-acidification of the thylakoid lumen. Therefore, the contribution of CEF to total photosynthetic electron transport under FL changed diurnally according to the incident PSI redox state in a given condition.
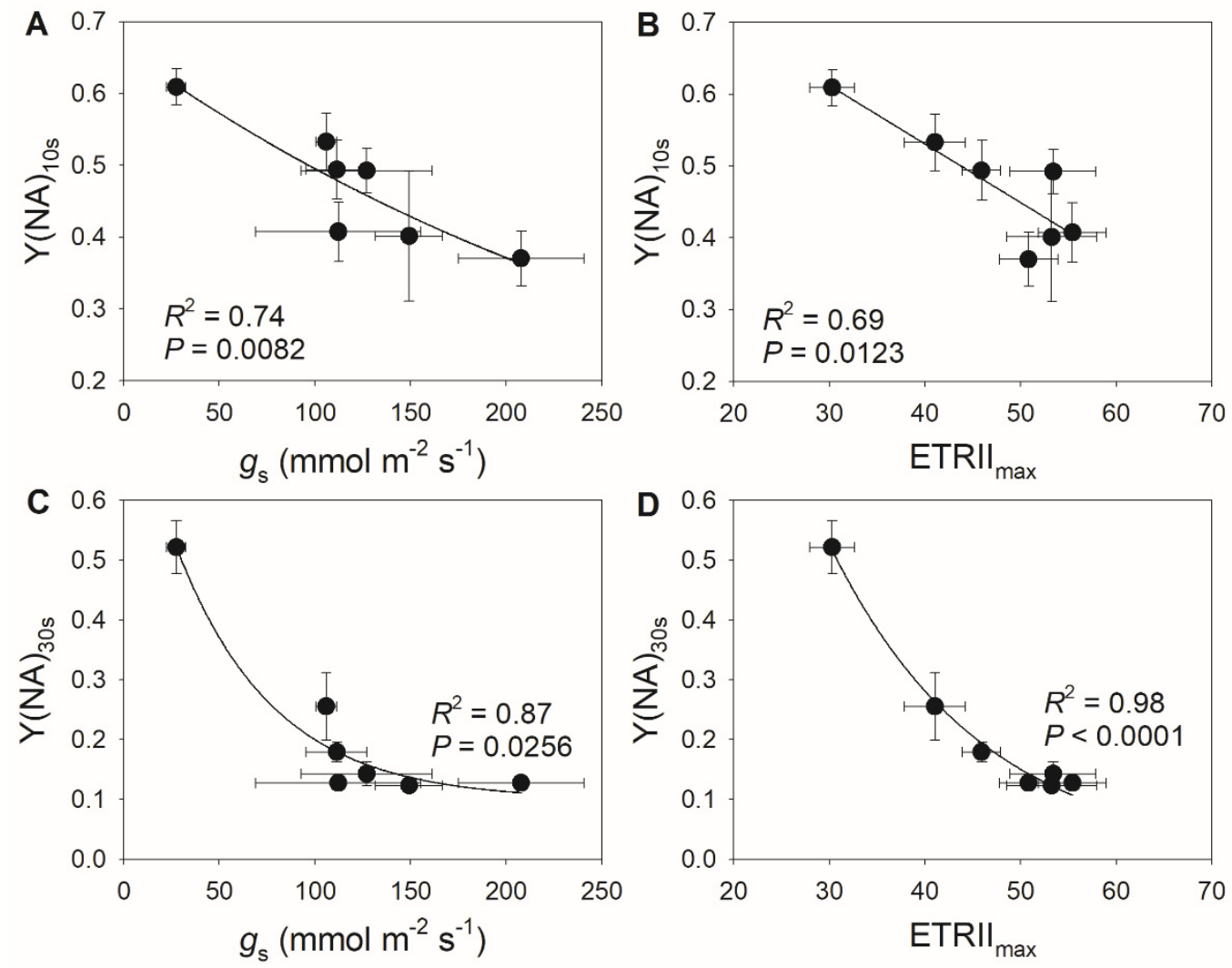

Figure 5. Relationships between (A) stomatal conductance $\left(g_{\mathrm{s}}\right)$ and $\mathrm{Y}(\mathrm{NA})$ after transition from low to high light for $10 \mathrm{~s}\left(\mathrm{Y}(\mathrm{NA})_{10} \mathrm{~s}\right)$, between (B) maximum electron transport rate through PSII $\left(\right.$ ETRII $\left._{\max }\right)$ and $\mathrm{Y}(\mathrm{NA})_{10 \mathrm{~s}}$, between $(\mathrm{C})$ stomatal conductance $\left(g_{\mathrm{s}}\right)$ and $\mathrm{Y}(\mathrm{NA})$ after transition from low to high light for $30 \mathrm{~s}\left(\mathrm{Y}(\mathrm{NA})_{30 \mathrm{~s}}\right)$, and between (D) ETRII $\max$ and $\mathrm{Y}(\mathrm{NA})_{30 \mathrm{~s}}$ in M. alba leaves. All data are from Figure 4.

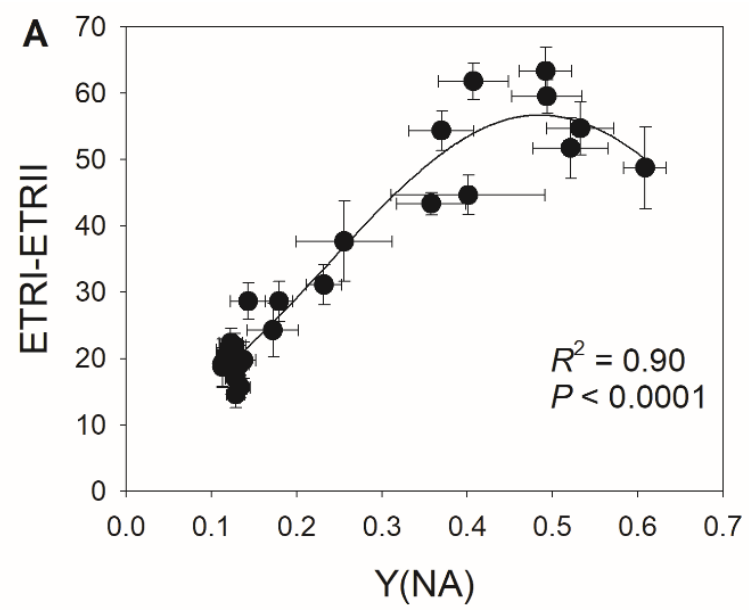

Figure 6. Cont. 


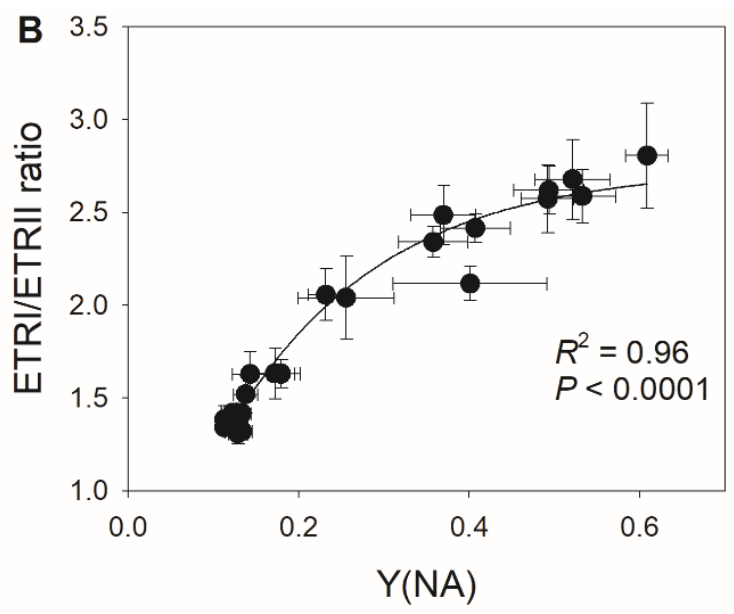

Figure 6. Relationships between (A) Y(NA) and ETRI-ETRII and between (B) Y(NA) and the ETRI/ERTII ratio during the high light phases under fluctuating light in $M$. alba leaves. Data are shown as mean \pm SE $(n=6)$.

\section{Discussion}

After transitioning from low to high light, tomato and M. alba leaves displayed a significant transient over-reduction of PSI (Figures 1D and 4D), indicating that the electrons transported to PSI failed to be immediately consumed by the downstream sinks of PSI. Furthermore, this suggested that the water-water cycle had a negligible contribution in tomato and M. alba, as it rapidly consumed the excess reducing power of PSI $[11,36,38]$. Therefore, the electrons transported from PSII to PSI are mainly channeled toward $\mathrm{CO}_{2}$ fixation and photorespiration. During diurnal changes in photosynthetic rates, the decrease in stomatal conductance was accompanied by lower PSII electron flow (Figures 1 and 4), indicating that $\mathrm{CO}_{2}$ assimilation was restricted at low stomatal conductance. Under these conditions, the extent of PSI over-reduction within the first $10 \mathrm{~s}$ after transition from low to high light was aggravated. Furthermore, when stomatal conductance decreased in the late afternoon, we also observed PSI over-reduction under FL after transition from low to high light for $30 \mathrm{~s}$. These results suggested that the restriction of $\mathrm{CO}_{2}$ assimilation by low stomatal conductance significantly induced stronger and prolonged PSI over-reduction under FL. PSI over-reduction increases the transfer of electrons to $\mathrm{O}_{2}$, resulting in the generation of ROS in the vicinity of PSI and thus causing PSI photoinhibition $[8,9,52,53]$. Therefore, PSI susceptibility to photoinhibition under FL can be affected by stomatal conductance.

Stomatal conductance is an important factor determining light use efficiency under FL [54-56]. During the diurnal course of photosynthesis, stomatal opening under high-light conditions increases the $\mathrm{CO}_{2}$ diffusion efficiency and facilitates $\mathrm{CO}_{2}$ assimilation $[43,57]$. Interestingly, this study determined that stomatal opening could alleviate PSI over-reduction under FL (Figures 2 and 5), which would diminish or prevent FL-induced PSI photoinhibition. When PSI is damaged, photosynthetic electron transport systems including LEF and CEF are suppressed, leading to a lower trans-thylakoid proton gradient and a loss of photoprotection for PSI and PSII [14,16,58]. Photosynthetic $\mathrm{CO}_{2}$ assimilation is also restricted by the lack of ATP and NADPH $[13,59,60]$. Therefore, maintaining PSI activity is a prerequisite for highly efficient $\mathrm{CO}_{2}$ assimilation under FL during diurnal photosynthesis [61]. Accordingly, the diurnal stomatal opening under high light is important for protecting PSI under FL and thus guaranteeing optimal photosynthesis over the course of the day.

Recent studies have reported that increased stomatal conductance can enhance both $\mathrm{CO}_{2}$ assimilation rate and biomass production under FL in rice and Arabidopsis $[43,57]$, which holds great potential for crop improvement and molecular breeding. A possible explanation for these observations is that the increased conductance lowers the stomatal limitation of photosynthesis by accelerating the diffusion of $\mathrm{CO}_{2}$ into leaves, to ensure 
efficient photosynthetic $\mathrm{CO}_{2}$ fixation. In rice and Arabidopsis, PSI is susceptible to photoinhibition under FL, which leads to significant decreases in $\mathrm{CO}_{2}$ assimilation rates and biomass when grown under FL [4,6]. Therefore, preventing FL-induced PSI photoinhibition can facilitate sustained high photosynthetic efficiency under FL. In this study, higher stomatal conductance significantly lowered PSI over-reduction under FL (Figures 2 and 5). Therefore, the artificial enhancement of stomatal opening by FL in rice and Arabidopsis will favor PSI photoprotection and thus guarantee photosynthetic reactions, providing a basis for the increase in plant biomass.

Upon transitioning from low to high light, the dynamic flexibility of CEF activity regulates the trade-off between photoprotection and photosynthetic efficiency [30,62]. Within the first seconds after changing from low to high light, CEF was highly activated to help generate the $\Delta \mathrm{pH}$ necessary for ATP production, which strengthens photosynthetic control of cytochrome $b_{6} f$ and enhances electron transport downstream of PSI [6,10,22]. As a result, this transient CEF stimulation prevents uncontrolled PSI over-reduction under FL $[6,8]$. When PSI over-reduction is clearly absent, CEF activity decreases to prevent over-acidification of the thylakoid lumen $[22,24,63]$, thus optimizing photosynthetic efficiency [64]. Consistently, we observed that moderate PSI over-reduction under FL induced the greatest CEF activation in both plant species (Figures 3 and 6). Furthermore, we noticed an unexpected inhibition of CEF by severe PSI over-reduction under low stomatal conductance (Figures 3 and 6). When Y(NA) was greater than 0.6, the small number of photo-oxidizable P700 donors in PSI was not sufficient to maintain the normal operation of the CEF. Such an inhibition of the CEF limited $\triangle \mathrm{pH}$ formation, leading to prolonged PSI over-reduction under FL at low stomatal conductance (Figures 1D and 4D). Therefore, stomatal conductance can have a large effect on thylakoid reactions under FL.

\section{Conclusions}

In this study, we examined the regulation of photosynthesis over the diurnal cycle under FL in tomato and Morus alba. The FL-induced over-reduction of PSI was modest at noon but was severe in the late afternoon. Furthermore, the diurnal response of PSI to FL was largely affected by photosynthetic efficiency, which itself was mainly influenced by stomatal conductance. A relatively high stomatal conductance at noon not only ensures efficient photosynthetic $\mathrm{CO}_{2}$ assimilation, but also favors PSI photoprotection under FL. Our results provide new insight into the physiological function of stomatal conductance in sustaining photosynthesis over the course of the day.

Author Contributions: Conceptualization, W.H. and S.-B.Z.; methodology, T.-Y.L. and Q.S.; validation, S.-B.Z. and W.H.; investigation, T.-Y.L., Q.S. and H.S.; data curation, T.-Y.L. and Q.S.; writingoriginal draft preparation, W.H.; writing—review and editing, M.Y. and S.-B.Z.; visualization, Q.S.; project administration, S.-B.Z. and W.H.; funding acquisition, W.H. All authors have read and agreed to the published version of the manuscript.

Funding: This work was supported by the National Natural Science Foundation of China (Grant 31971412), and the Project for Innovation Team of Yunnan Province.

Data Availability Statement: The data presented in this study are available on request from the corresponding author.

Conflicts of Interest: The authors declare no conflict of interest.

\section{References}

1. Valladares, F.; Allen, M.T.; Pearcy, R.W. Photosynthetic responses to dynamic light under field conditions in six tropical rainforest shrubs occurring along a light gradient. Oecologia 1997, 111, 505-514. [CrossRef] [PubMed]

2. Chen, Y.; Xu, D.Q. Two patterns of leaf photosynthetic response to irradiance transition from saturating to limiting one in some plant species. New Phytol. 2006, 169, 789-798. [CrossRef]

3. Yang, Y.-J.; Zhang, S.-B.; Wang, J.-H.; Huang, W. The decline in photosynthetic rate upon transfer from high to low light is linked to the slow kinetics of chloroplast ATP synthase in Bletilla striata. Photosynth. Res. 2020, 144, 13-21. [CrossRef] 
4. Yamori, W.; Makino, A.; Shikanai, T. A physiological role of cyclic electron transport around photosystem I in sustaining photosynthesis under fluctuating light in rice. Sci. Rep. 2016, 6, 20147. [CrossRef] [PubMed]

5. Yamamoto, H.; Takahashi, S.; Badger, M.R.; Shikanai, T. Artificial remodelling of alternative electron flow by flavodiiron proteins in Arabidopsis. Nat. Plants 2016, 2, 16012. [CrossRef] [PubMed]

6. Yamamoto, H.; Shikanai, T. PGR5-dependent cyclic electron flow protects photosystem I under fluctuating light at donor and acceptor sides. Plant Physiol. 2019, 179, 588-600. [CrossRef]

7. Huang, W.; Yang, Y.-J.; Zhang, S.-B. Photoinhibition of photosystem I under fluctuating light is linked to the insufficient $\Delta \mathrm{pH}$ upon a sudden transition from low to high light. Environ. Exp. Bot. 2019, 160, 112-119. [CrossRef]

8. Suorsa, M.; Jarvi, S.; Grieco, M.; Nurmi, M.; Pietrzykowska, M.; Rantala, M.; Kangasjarvi, S.; Paakkarinen, V.; Tikkanen, M.; Jansson, S.; et al. PROTON GRADIENT REGULATION5 is essential for proper acclimation of Arabidopsis photosystem I to naturally and artificially fluctuating light conditions. Plant Cell 2012, 24, 2934-2948. [CrossRef] [PubMed]

9. Takagi, D.; Takumi, S.; Hashiguchi, M.; Sejima, T.; Miyake, C. Superoxide and singlet oxygen produced within the thylakoid membranes both cause photosystem I photoinhibition. Plant Physiol. 2016, 171, 1626-1634. [CrossRef]

10. Kono, M.; Noguchi, K.; Terashima, I. Roles of the cyclic electron flow around PSI (CEF-PSI) and O2-dependent alternative pathways in regulation of the photosynthetic electron flow in short-term fluctuating light in Arabidopsis thaliana. Plant Cell Physiol. 2014, 55, 990-1004. [CrossRef]

11. Huang, W.; Yang, Y.-J.; Zhang, S.-B. The role of water-water cycle in regulating the redox state of photosystem I under fluctuating light. Biochim. Biophys. Acta Bioenerg. 2019, 1860, 383-390. [CrossRef]

12. Tan, S.-L.; Yang, Y.-J.; Liu, T.; Zhang, S.-B.; Huang, W. Responses of photosystem I compared with photosystem II to combination of heat stress and fluctuating light in tobacco leaves. Plant Sci. 2020, 292, 110371. [CrossRef]

13. Sejima, T.; Takagi, D.; Fukayama, H.; Makino, A.; Miyake, C. Repetitive short-pulse light mainly inactivates photosystem i in sunflower leaves. Plant Cell Physiol. 2014, 55, 1184-1193. [CrossRef] [PubMed]

14. Zivcak, M.; Brestic, M.; Kunderlikova, K.; Sytar, O.; Allakhverdiev, S.I. Repetitive light pulse-induced photoinhibition of photosystem I severely affects $\mathrm{CO}_{2}$ assimilation and photoprotection in wheat leaves. Photosynth. Res. 2015, 126, $449-463$. [CrossRef]

15. Munekage, Y.N.; Genty, B.; Peltier, G. Effect of PGR5 impairment on photosynthesis and growth in Arabidopsis thaliana. Plant Cell Physiol. 2008, 49, 1688-1698. [CrossRef] [PubMed]

16. Brestic, M.; Zivcak, M.; Kunderlikova, K.; Allakhverdiev, S.I. High temperature specifically affects the photoprotective responses of chlorophyll b-deficient wheat mutant lines. Photosynth. Res. 2016, 130, 251-266. [CrossRef] [PubMed]

17. Nawrocki, W.J.; Bailleul, B.; Cardol, P.; Rappaport, F.; Wollman, F.A.; Joliot, P. Maximal cyclic electron flow rate is independent of PGRL1 in Chlamydomonas. Biochim. Biophys. Acta Bioenerg. 2019, 1860, 425-432. [CrossRef]

18. Nawrocki, W.J.; Bailleul, B.; Picot, D.; Cardol, P.; Rappaport, F.; Wollman, F.A.; Joliot, P. The mechanism of cyclic electron flow. Biochim. Biophys. Acta Bioenerg. 2019, 1860, 433-438. [CrossRef] [PubMed]

19. Wang, C.; Yamamoto, H.; Shikanai, T. Role of cyclic electron transport around photosystem I in regulating proton motive force. Biochim. Biophys. Acta 2015, 1847, 931-938. [CrossRef]

20. Storti, M.; Segalla, A.; Mellon, M.; Alboresi, A.; Morosinotto, T. Regulation of electron transport is essential for photosystem I stability and plant growth. New Phytol. 2020, 228, 1316-1326. [CrossRef]

21. Nakano, H.; Yamamoto, H.; Shikanai, T. Contribution of NDH-dependent cyclic electron transport around photosystem I to the generation of proton motive force in the weak mutant allele of pgr5. Biochim. Biophys. Acta Bioenerg. 2019, 1860, 369-374. [CrossRef] [PubMed]

22. Yang, Y.-J.; Ding, X.-X.; Huang, W. Stimulation of cyclic electron flow around photosystem I upon a sudden transition from low to high light in two angiosperms Arabidopsis thaliana and Bletilla striata. Plant Sci. 2019, 287, 110166. [CrossRef] [PubMed]

23. Tan, S.-L.; Yang, Y.-J.; Huang, W. Moderate heat stress accelerates photoinhibition of photosystem I under fluctuating light in tobacco young leaves. Photosynth. Res. 2020, 144, 373-382. [CrossRef]

24. Tan, S.-L.; Huang, J.-L.; Zhang, F.-P.; Zhang, S.-B.; Huang, W. Photosystem I photoinhibition induced by fluctuating light depends on background low light irradiance. Environ. Exp. Bot. 2021, 181, 104298. [CrossRef]

25. Tikkanen, M.; Aro, E.M. Integrative regulatory network of plant thylakoid energy transduction. Trends Plant Sci. 2014, 19, 10-17. [CrossRef]

26. Sun, H.; Zhang, S.-B.; Liu, T.; Huang, W. Decreased photosystem II activity facilitates acclimation to fluctuating light in the understory plant Paris polyphylla. Biochim. Biophys. Acta Bioenerg. 2020, 1861, 148135. [CrossRef]

27. Ilík, P.; Pavlovič, A.; Kouřil, R.; Alboresi, A.; Morosinotto, T.; Allahverdiyeva, Y.; Aro, E.M.; Yamamoto, H.; Shikanai, T. Alternative electron transport mediated by flavodiiron proteins is operational in organisms from cyanobacteria up to gymnosperms. New Phytol. 2017, 214, 967-972. [CrossRef]

28. Tazoe, Y.; Ishikawa, N.; Shikanai, T.; Ishiyama, K.; Takagi, D.; Makino, A.; Sato, F.; Endo, T. Overproduction of PGR5 enhances the electron sink downstream of photosystem I in a C 4 plant, Flaveria bidentis. Plant J. 2020, 103, 814-823. [CrossRef]

29. Wada, S.; Yamamoto, H.; Suzuki, Y.; Yamori, W.; Shikanai, T.; Makino, A. Flavodiiron protein substitutes for cyclic electron flow without competing CO2 assimilation in rice. Plant Physiol. 2018, 176, 1509-1518. [CrossRef] [PubMed]

30. Alboresi, A.; Storti, M.; Morosinotto, T. Balancing protection and efficiency in the regulation of photosynthetic electron transport across plant evolution. New Phytol. 2019, 221, 105-109. [CrossRef] [PubMed] 
31. Shikanai, T.; Yamamoto, H. Contribution of cyclic and pseudo-cyclic electron transport to the formation of proton motive force in chloroplasts. Mol. Plant 2017, 10, 20-29. [CrossRef] [PubMed]

32. Asada, K. The water-water cycle in chloroplasts: Scavenging of active oxygens and dissipation of excess photons. Annu. Rev. Plant Physiol. Plant Mol. Biol. 1999, 50, 601-639. [CrossRef] [PubMed]

33. Shirao, M.; Kuroki, S.; Kaneko, K.; Kinjo, Y.; Tsuyama, M.; Förster, B.; Takahashi, S.; Badger, M.R. Gymnosperms have increased capacity for electron leakage to oxygen (Mehler and PTOX reactions) in photosynthesis compared with angiosperms. Plant Cell Physiol. 2013, 54, 1152-1163. [CrossRef] [PubMed]

34. Driever, S.M.; Baker, N.R. The water-water cycle in leaves is not a major alternative electron sink for dissipation of excess excitation energy when $\mathrm{CO}_{2}$ assimilation is restricted. Plant Cell Environ. 2011, 34, 837-846. [CrossRef] [PubMed]

35. Badger, M.R.; von Caemmerer, S.; Ruuska, S.; Nakano, H. Electron flow to oxygen in higher plants and algae: Rates and control of direct photoreduction (Mehler reaction) and rubisco oxygenase. Philos. Trans. R. Soc. London. Ser. B Biol. Sci. 2000, 355, 1433-1446. [CrossRef]

36. Sun, H.; Yang, Y.-J.; Huang, W. The water-water cycle is more effective in regulating redox state of photosystem I under fluctuating light than cyclic electron transport. Biochim. Biophys. Acta Bioenerg. 2020, 1861, 148235. [CrossRef]

37. Yang, Y.-J.; Zhang, S.-B.; Huang, W. Photosynthetic regulation under fluctuating light in young and mature leaves of the CAM plant Bryophyllum pinnatum. Biochim. Biophys. Acta Bioenerg. 2019, 1860, 469-477. [CrossRef] [PubMed]

38. Yang, Y.-J.; Tan, S.-L.; Huang, J.-L.; Zhang, S.-B.; Huang, W. The water-water cycle facilitates photosynthetic regulation under fluctuating light in the epiphytic orchid Dendrobium officinale. Environ. Exp. Bot. 2020, 180, 104238. [CrossRef]

39. Kono, M.; Terashima, I. Elucidation of photoprotective mechanisms of PSI against fluctuating light photoinhibition. Plant Cell Physiol. 2016, 57, 1405-1414. [CrossRef]

40. Kono, M.; Terashima, I. Long-term and short-term responses of the photosynthetic electron transport to fluctuating light. J. Photochem. Photobiol. B Biol. 2014, 137, 89-99. [CrossRef] [PubMed]

41. Matthews, J.S.; Vialet-Chabrand, S.R.; Lawson, T. Acclimation to fluctuating light impacts the rapidity and diurnal rhythm of stomatal conductance. Plant Physiol. 2018, 176, 1939-1951. [CrossRef]

42. Slattery, R.A.; Walker, B.J.; Weber, A.P.M.; Ort, D.R. The impacts of fluctuating light on crop performance. Plant Physiol. 2018, 176, 990-1003. [CrossRef]

43. Yamori, W.; Kusumi, K.; Iba, K.; Terashima, I. Increased stomatal conductance induces rapid changes to photosynthetic rate in response to naturally fluctuating light conditions in rice. Plant Cell Environ. 2020, 43, 1230-1240. [CrossRef] [PubMed]

44. Sakoda, K.; Yamori, W.; Groszmann, M.; Evans, J.R. Stomatal, mesophyll conductance, and biochemical limitations to photosynthesis during induction Research Article. Plant Physiol. 2021, 185, 146-160. [CrossRef] [PubMed]

45. Joliot, P.; Johnson, G.N. Regulation of cyclic and linear electron flow in higher plants. Proc. Natl. Acad. Sci. USA 2011, 108, 13317-13322. [CrossRef] [PubMed]

46. Zivcak, M.; Brestic, M.; Balatova, Z.; Drevenakova, P.; Olsovska, K.; Kalaji, H.M.; Yang, X.; Allakhverdiev, S.I. Photosynthetic electron transport and specific photoprotective responses in wheat leaves under drought stress. Photosynth. Res. 2013, 117, 529-546. [CrossRef]

47. Schreiber, U.; Klughammer, C. Non-photochemical fluorescence quenching and quantum yields in PS I and PS II: Analysis of heat-induced limitations using Maxi-Imaging- PAM and Dual-PAM-100. PAM Appl. Notes 2008, 1, 15-18. [CrossRef]

48. Hepworth, C.; Wood, W.H.J.; Emrich-Mills, T.Z.; Proctor, M.S.; Casson, S.; Johnson, M.P. Dynamic thylakoid stacking and state transitions work synergistically to avoid acceptor-side limitation of photosystem I. Nat. Plants 2021, 7, 87-98. [CrossRef] [PubMed]

49. Huang, W.; Yang, S.J.; Zhang, S.B.; Zhang, J.L.; Cao, K.F. Cyclic electron flow plays an important role in photoprotection for the resurrection plant Paraboea rufescens under drought stress. Planta 2012, 235, 819-828. [CrossRef] [PubMed]

50. Furutani, R.; Ifuku, K.; Suzuki, Y.; Noguchi, K.; Shimakawa, G.; Wada, S.; Makino, A.; Sohtome, T.; Miyake, C. P700 oxidation suppresses the production of reactive oxygen species in photosystem I. In Advances in Botanical Research; Elsevier: Amsterdam, The Netherlands, 2020; Volume 96, pp. 151-176. ISBN 9780081028964.

51. Shimakawa, G.; Miyake, C. Photosynthetic Linear Electron Flow Drives CO2 Assimilation in Maize Leaves. Int. J. Mol. Sci. 2021, 22, 4894. [CrossRef] [PubMed]

52. Takagi, D.; Amako, K.; Hashiguchi, M.; Fukaki, H.; Ishizaki, K.; Goh, T.; Fukao, Y.; Sano, R.; Kurata, T.; Demura, T.; et al. Chloroplastic ATP synthase builds up a proton motive force preventing production of reactive oxygen species in photosystem I. Plant J. 2017, 91, 306-324. [CrossRef] [PubMed]

53. Tikkanen, M.; Mekala, N.R.; Aro, E.-M. Photosystem II photoinhibition-repair cycle protects Photosystem I from irreversible damage. Biochim. Biophys. Acta 2014, 1837, 210-215. [CrossRef]

54. De Souza, A.P.; Wang, Y.; Orr, D.J.; Carmo-Silva, E.; Long, S.P. Photosynthesis across African cassava germplasm is limited by Rubisco and mesophyll conductance at steady state, but by stomatal conductance in fluctuating light. New Phytol. 2020, 225, 2498-2512. [CrossRef]

55. Tanaka, Y.; Adachi, S.; Yamori, W. Natural genetic variation of the photosynthetic induction response to fluctuating light environment. Curr. Opin. Plant Biol. 2019, 49, 52-59. [CrossRef] [PubMed]

56. Sakoda, K.; Yamori, W.; Shimada, T.; Sugano, S.S.; Hara-Nishimura, I.; Tanaka, Y. Higher stomatal density improves photosynthetic induction and biomass production in Arabidopsis under fluctuating light. Front. Plant Sci. 2020, 11, 1308. [CrossRef] [PubMed] 
57. Kimura, H.; Hashimoto-Sugimoto, M.; Iba, K.; Terashima, I.; Yamori, W. Improved stomatal opening enhances photosynthetic rate and biomass production in fluctuating light. J. Exp. Bot. 2020, 71, 2339-2350. [CrossRef] [PubMed]

58. Shimakawa, G.; Miyake, C. What quantity of photosystem I is optimum for safe photosynthesis? Plant Physiol. 2019, 179, 1479-1485. [CrossRef]

59. Brestic, M.; Zivcak, M.; Kunderlikova, K.; Sytar, O.; Shao, H.; Kalaji, H.M.; Allakhverdiev, S.I. Low PSI content limits the photoprotection of PSI and PSII in early growth stages of chlorophyll b-deficient wheat mutant lines. Photosynth. Res. 2015, 125, 151-166. [CrossRef]

60. Lima-Melo, Y.; Gollan, P.J.; Tikkanen, M.; Silveira, J.A.G.; Aro, E.M. Consequences of photosystem-I damage and repair on photosynthesis and carbon use in Arabidopsis thaliana. Plant J. 2019, 97, 1061-1072. [CrossRef]

61. Huang, W.; Yang, Y.-J.; Hu, H.; Cao, K.-F.; Zhang, S.-B. Sustained Diurnal Stimulation of Cyclic Electron Flow in Two Tropical Tree Species Erythrophleum guineense and Khaya ivorensis. Front. Plant Sci. 2016, 7, 1068. [CrossRef] [PubMed]

62. Armbruster, U.; Correa Galvis, V.; Kunz, H.H.; Strand, D.D. The regulation of the chloroplast proton motive force plays a key role for photosynthesis in fluctuating light. Curr. Opin. Plant Biol. 2017, 37, 56-62. [CrossRef] [PubMed]

63. Huang, W.; Hu, H.; Zhang, S.B. Photosynthetic regulation under fluctuating light at chilling temperature in evergreen and deciduous tree species. J. Photochem. Photobiol. B Biol. 2021, 219, 112203. [CrossRef] [PubMed]

64. Rott, M.; Martins, N.F.; Thiele, W.; Lein, W.; Bock, R.; Kramer, D.M.; Schöttler, M.A. ATP Synthase Repression in Tobacco Restricts Photosynthetic Electron Transport, $\mathrm{CO}_{2}$ Assimilation, and Plant Growth by Overacidification of the Thylakoid Lumen. Plant Cell 2011, 23, 304-321. [CrossRef] [PubMed] 